\title{
A Educação Brasileira do Futuro: Inclusão Étnica e Diversidade Cultural.
}

(The Brazilian Education of the Future: Ethnic Inclusion and Cultural Diversity.)

Ralph Siqueira Pires

Universidad San Lorenzo Paraguay e Ensino Estadual Rio de Janeiro- Brasil

Fecha recepción: 01-08-2018

Páginas 89-100

Fecha aceptación: 30-09-2018

\section{Resumo.}

Este artigo buscou compreender a questão da inclusão enquanto comprometimento no campo da educação em aspecto geral, para a minoria, entre elas, a dos povos originários "indígenas" brasileiros. O objetivo buscou compreender melhor a educação inclusiva enquanto comprometimento para a população indígena brasileira. 0 estudo teve abordagem qualitativa do tipo descritiva com base em revisões bibliográficas foi possível coletar os dados. Enquanto resultado, todavia se prega a teoria da ação antidialógica a qual impera em grande parte das relações humanas e sociais. A invasão cultural continua se servindo de expansão de domínios e conquistas, desrespeitando potencialidades do ser que, em muitas das vezes, condiciona este processo de mudanças. Contudo, se faz necessário buscar novos subsídios para que se efetive na prática soluções viáveis para uma educação inclusiva ainda, que em um futuro próximo.

Palavras-Chave: diversidade; étnica; cultura; educação; inclusão

Abstract.

This article sought to understand the issue of inclusion as a commitment in the field of education in general aspect, for the minority, among them, that of the native "indigenous" Brazilian peoples. The objective was to better understand inclusive education as a commitment to the Brazilian indigenous population. The study had qualitative approach of the descriptive type based on bibliographic revisions it was possible to collect the data. As a result, however, the antidialogic theory of action is preached which dominates much of human and social relations. The cultural invasion continues to serve as an expansion of domains and conquests, disrespecting the potentialities of the being that, in many cases, conditions this process of change. However, it is necessary to seek new subsidies só that viable solutions for an inclusive education can be implemented in practice in the near future.

Keywords: diversity; ethnic; culture; education; inclusion 


\section{1.-Introdução.}

A importância deste artigo é ampliar a perspectiva e a repercussão da necessidade de se desenvolver crescentemente a travessia dialógico de educadores e afins, e de educandos em geral. Em especial, pelo debate da inclusão étnica mediante a diversidade cultural e a necessidade da interculturalidade crítica, no sentido de se construir uma Educação do Futuro pautada no bem comum humano e mundial.

Assim sendo, o artigo buscou compreender melhor a questão da inclusão enquanto comprometimento no que tange a educação brasileira no aspecto geral no que tange as minorias, entre elas, dos povos originários brasileiros. Identificar o pensar, as manifestações e a demanda dentre outras expressões e ações em especial destas minorias ainda excluídas.

Assim sendo o estudo se dá devido as grandes mudanças sociais, as inovações tecnológicas frente ao texto constitucional 1988 que assegurou, no que se refere ao campo educacional, 0 direito das sociedades indígenas de terem uma educação escolar diferenciada, específica, intercultural e bilíngue, libertando-se da tutela do Estado, caminhando rumo a uma desejada autonomia e necessária interculturalidade.

\section{2.-Uma breve apresentação de aspectos étnicos relevantes.}

No que se refere a questão indígena, é preciso dizer que no último censo demográfico do IBGE (2010) contou-se 896.917 indígenas, sendo que deste total 379.534 mil vivem em áreas urbanas. Segundo dados apresentados por este estudo, a população indígena aumentou em comparação ao censo/2000. E, somente no Rio de Janeiro a população indígena diminuiu. $\mathrm{E}$, de acordo com os números, no censo demográfico de 2000, eram 35.934 indígenas, sendo 15.622 na capital, e em 2010, 15.894 no estado e 6.764 na capital. Sendo o Rio de Janeiro um dos estados mais ricos, como se explica esta diminuição populacional de $8,0 \%$ na capital e $7,7 \%$ nas outras cidades.

\section{1.-Algumas questões sobre a questão da diversidade cultural.}

Outro ponto relevante é a da diversidade cultural indígena no Brasil, configurando-se, neste ângulo, um total de 305 etnias e 274 línguas. Neste último aspecto, é preciso se considerar também a mistura de línguas. O "português-indígena" é o que ocorre na maioria das etnias, e uma fonte de estudos do departamento de ciências aplicadas à educação da Universidade Federal de Minas Gerais (UFMG). Este bilinguismo é fenômeno a se pensar semelhante ao portunhol que é o dialeto de fronteira do Brasil com o Uruguai.

Aprofundando-se um pouco mais o assunto relativo a educação e as línguas, considera-se a narração de Gervásio Siqueira Pires (1921-2018), migrante nordestino, morador do Rio de Janeiro há quase setenta anos. Contava o mesmo que "na década de 1930, as crianças que falavam línguas nativas por laço de 
parentesco para que não falassem enrolado, quando iam para a escola, eram surrados pela palmatória", ou seja, pelo antigo instrumento de tortura que remonta 0 tempo da escravidão, e era utilizado amplamente na "alfabetização" de crianças desta época.

Segundo o informante, representante da memória e voz popular, isto acontecia no sertão pernambucano, na cidade de Senharo de Pesqueiro e também em Bom Conselho de Papa-caça, locais onde morou e estudou quando criança. Cidades estas do interior de Pernambuco que através destes, e de outros procedimentos violentos, em muito reprimiram a expressividades étnicas Fulni-ô e Xucuru que continuam até hoje resistindo e afirmando-se culturalmente em meio a política educacional nacional silenciadora das populações nativas.

\section{3.-Metodologia.}

\section{1.-Desenho da pesquisa.}

Para se realizar este estudo, seguiu-se as abordagem qualitativa do tipo revisão bibliográfica pelo levantamento de informações e, também, de assuntos pertinentes a discussão sobre questões relativas a uma inovadora proposta educacional e inclusiva naquilo que se refere à diversidade étnica e cultural indígena.

Para Marconi e Lakatos (2009) "toda pesquisa implica o levantamento de dados de várias fontes, quaisquer que sejam os métodos ou técnicas empregadas". Por isso para toda pesquisa utilizamos técnicas para poder chegar ao resultado e propósitos estabelecidos, numa pesquisa considera um levantamento de dados de fontes, observando à temática, onde nesta fase recorremos as informações previas.

\section{2.-Fontes dos dados da pesquisa.}

Marconi e Lakatos (2009) citam algumas fontes de documentos usadas na pesquisa bibliográfica e que exigem do pesquisador alguns procedimentos e análises diferentes como, publicações compreende o conjunto de publicações que podem ser os livros, as pesquisas, as teses, entre outros, em que o seu uso depende de quatro fases, a identificação, localização, compilação e fichamento. Os instrumentos utilizados para coleta de dados desta pesquisa foi, uma lista de observação que foi elaborada afim de encontrar os dados da pesquisa.

\section{3.-Analises dos dados.}

Foram citadas e discutidas algumas ideias dos educadores e/ou pensadores Nestor Canclini, Edgar Morin e Paulo Freire, no sentido de ampliação de perspectivas das propostas educacionais rumo a um futuro realmente inclusivo. Além da citação de dados relevantes sobre etnicidade e diversidade cultural brasileira. Como também alguns pontos de desenvolvimento inicial da pesquisa participante em eventos ocorridos na Aldeia Maracanã, CESAC e outros. 
Os dados coletados foram tratados de acordo com os procedimentos técnicos da análise de conteúdo, que segundo Bardin (2005) caracteriza-se por um conjunto de técnicas de análise das comunicações visando a obter, por procedimentos sistemáticos e objetivos de descrição do conteúdo das mensagens, indicadores (quantitativos ou não) que permitam a inferência de conhecimentos relativos às condições de produção/recepção (variáveis inferidas) destas mensagens (Bardin, 2005, p. 47).

\section{4.-Discussão dos Resultados.}

Pode-se considerar que as questões educacionais brasileiras melhoraram, sobretudo, a partir das legalidades constitucionais de 1988, por garantirem aos povos originários uma educação indígena dentro dos seus territórios. Mesmo que nem sempre aconteça na prática.

Mas nem tudo são realmente flores nos caminhos das populações indígenas.

Tabela 01: Situação de algumas tribos indígenas no Mato Grosso do Sul.

Dados sobre a situação de algumas tribos indígenas no Mato Grosso do Sul.

Resultados

No estado do Mato Grosso do Sul entre 2003 e 2014, 390 indígenas foram assassinados por ordem de latifundiários. Em 29 de setembro de 2015 foi assassinado Simão Vilhalva, uma liderança dos povos indígenas guarani kaiowás. Trinta dias seguintes a este acontecimento, mais de 4.000 indígenas foram torturados e expulsos de suas terras como denunciou uma outra liderança indígena da região num debate na Universidade do estado do Rio de Janeiro (UERJ) juntamente com a Ordem dos Advogados do Brasil (OAB) /RJ.

Fonte: A própria pesquisa.

Estas violações aos direitos humanos indígenas não ocorrem somente em um estado brasileiro. O Mato Grosso do Sul é um dos que responde por $52 \%$ dos casos de assassinatos de indígenas cometidos por latifundiários, registrados no Brasil, considerado o estado mais violento contra os indígenas, segundo o Conselho Indígena Missionário (CIMI).

Tabela 02: A situação da educação indígenas presentes no Rio de Janeiro.

Resultados encontrados sobre a situação da educação indígenas presentes no Rio de Janeiro.

No Rio de Janeiro em outubro de 2006, vinte etnias indígenas de três troncos linguísticos realizaram o Congresso Tamoio dos Povos Originários, e daí decidiram ocupar um prédio que é dedicado a cultura indígena há mais de 150 anos. Este imóvel pertenceu ao antigo proprietário Duque de Saxe, e era o antigo Jóquei Club da nobreza colonial. Este decidiu fazer uma "doação" nos anos de 1850 com destinação "ad eternum" para destinação indígena, de 


\begin{tabular}{l|l}
\hline \multirow{3}{*}{ Resultados } & preservação e pesquisa de sementes e saberes indígenas. \\
\cline { 2 - 3 } & $\begin{array}{l}\text { O Marechal Rondon promoveu este imóvel em 1910, a sede do } \\
\text { recém-criado Serviço de Proteção ao Índio. E, a luta indigenista do } \\
\text { antropólogo Darcy Ribeiro transformou este local no Museu do Índio } \\
\text { entre os anos de } 1953 \text { e 1977, e que segundo a UNESCO foi "uma } \\
\text { concepção inovadora e original", sendo o embrião da Universidade } \\
\text { Rural do Rio de Janeiro, e também de cursos de Pós-graduação da } \\
\text { mesma instituição. No entanto, a ditadura militar em } 1978 \text { desativou } \\
\text { o prédio que ficou abandonado até o momento que o Movimento } \\
\text { Social Indígena reivindicou o espaço através da ocupação, } \\
\text { realizando-se ali um espaço de luta e de "formação da memória, } \\
\text { identidade sociocultural dos povos indígenas como patrimônio } \\
\text { imaterial". }\end{array}$
\end{tabular}

Fonte: A própria pesquisa.

Em verdade, o movimento indígena almeja consolidar um projeto de universidade indígena intercultural com cursos que possibilitem outras formações além da de professores. A aldeia Maracanã, como foi nomeada, resistiu até 2013, mas por ordem do governador por mandato judicial, em cumprimento de uma ordem arbitrária de exceção de direitos, convocou o batalhão de choque de forma truculenta a retirar os povos indígenas ali estalados, e entregou o prédio para a empresa Odebrecht, a mesma empresa que se vê envolvida em vários escândalos financeiros e políticos no país. Hoje este importante território ancestral "ad eternum", repetindo as palavras da nobreza colonial apropriadora original.

Tabela 03: Outros resultados sobre a situação indígenas.

Outros resultados sobre a situação indígenas.

0 ano de 2013 presenciou inúmeros levantes populares em todo o Brasil, os participantes da Aldeia Maracanã participaram do abril indígena, onde centenas de etnias ocuparam o Congresso Nacional com múltiplas reivindicações. Em outubro, o movimento indígena nacional retornou a Brasília para "comemorar" o $25^{\circ}$ aniversário da constituição de 1988, e procuraram denunciar o retrocesso dos direitos indígenas que estão em ocorrência. Estes espaços aqui citados foram realmente um verdadeiro cenário de interculturalidade, de articulação e de resistência, de estratégia e de formação a partir

Resultados dos conhecimentos coletivos, além de locus de pesquisa e educação.

Um ano depois (2014), foi então criado um Grupo de Trabalho (GT) com dezesseis integrantes subdivididos em três grupos: membros do SECADI/SESU (MEC), membros de algumas universidades brasileiras entre elas a UNICAMP/SP, UNB (DF), UFBA (BA) além de representantes indígenas para levarem a frente o debate da criação da Universidade Intercultural Indígena do Brasil, este coordenado pela nomeada secretaria de educação continuada, alfabetização, diversidade e inclusão ou do SECADI/MEC da situação. 
Fonte: A própria pesquisa.

Pode-se perceber que atualmente, o território está ocupado por uma diversidade de povos formadores da Aldeia Marakanã (Resistência - 2018). Estes vêm desenvolvendo várias ações que, agora com mais organicidade, buscam a consolidação do processo de criação de uma universidade indígena brasileira. Em novembro/2018 está planejado e em andamento a realização do $2^{\circ}$ COIREM, buscando-se novas definições e realizações a partir do apoio de amplas vertentes nacionais e internacionais que compreendem a importância de uma educação inclusiva mediante as perspectivas interculturais e os avanços dialógicos deste percurso em frente a um futuro mais pleno.

Resultados em números da situação da educação indígena no Brasil, divulgados pelo departamento de ciências aplicadas da UFMG.

Tabela 04: A situação da educação indígena no Brasil, divulgados pelo departamento de ciências aplicadas da UFMG.

\begin{tabular}{|c|c|}
\hline & 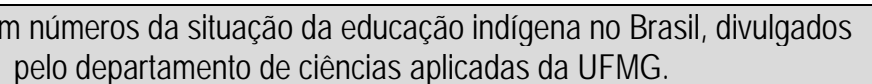 \\
\hline sultad & $\begin{array}{l}\text { Mas, para completar um pouco mais o quadro da situação atual da } \\
\text { educação escolar indígena, cita-se mais alguns números e } \\
\text { situações educacionais de nossos povos originários divulgados } \\
\text { pelo departamento de ciências aplicadas à educação da } \\
\text { Universidade Federal de Minas Gerais (UFMG): ou seja, são } \\
126.665 \text { estudantes indígenas matriculados nos anos iniciais - } \\
\text { regular e na Educação de Jovens e Adultos (EJA), contando com } \\
5214 \text { professores indígenas em atividade no Brasil, em } 2013 . \\
\text { Atualmente } 2.201 \text { professoras e professores indígenas estão em } \\
\text { formação sendo que em Manaus (AM), São Gabriel da Cachoeira } \\
\text { (AM) e Belém (PA). Destes, } 460 \text { professoras(es) concluíram neste } \\
\text { mesmo ano. }\end{array}$ \\
\hline
\end{tabular}

Estes números constituem a rede programa ação saberes indígenas na escola, e é composta por 24 instituições universitárias públicas entre elas USP, UFSC, UFES, UFRGS, UERJ, UFAM, UFPA entre outras. E, é coordenado pela já citada Universidade de Minas Gerais (UFMG) que tem como proposta promover a formação continuada de professores indígenas, a alfabetização bilíngue, e também a produção de material didático e paradidático com abordagem interdisciplinar.

Fonte: A própria pesquisa.

Assim sendo, declara Bruno Ferreira, um professor Kaigang, formado em História na UNIJUI, mestre em Educação da FACED da Universidade Federal do Rio Grande do Sul (UFRGS) que contribuiu através de seus estudos, participações e experiências na construção das diretrizes da educação indígena em todo Brasil como consultor do Ministério da Educação e Cultura (1990) "a educação diferenciada pressupõe 0 
respeito e a valorização do conhecimento tradicional (...) e a escola tem a função de dar valor para esses idosos que têm esse conhecimento."

Um outro número em destaque que se refere a questão da educação escolar indígena é a de que há 6.000 estudantes indígenas no ensino médio no Rio Grande do Sul, sendo este o resultado da implementação do artigo 265 da constituição do estado do Rio Grande do Sul que parece tratar com um pouco mais de atenção os direitos à educação dos indígenas.

Para finalizar esta discussão não se pode deixar de citar também o advento da nova Lei de Diretrizes e Bases da Educação (LDB) 1996 com artigos específicos sobre a educação escolar indígena. E, também a elaboração e publicação do Referencial Curricular Nacional para a Educação Indígenas por iniciativa do MEC em 1998.

Ou seja, com toda esta diversidade e "complexidade" que envolve a questão, e apesar das diversas formas de perseguições, exclusões e segregações, esta matriz da sociedade brasileira, os indígenas, tem seu modo de ser/saber/estar no mundo, tendo pois sua própria forma de se organizar e de se expressar, isto é, seus próprios mecanismos de transmissão de conhecimentos e de socialização de seus integrantes, ou umas tantas formas de educação indígena.

E, estas necessitam de espaço para dialogar com as novas propostas educacionais inclusivas provindas da cultura educacional e escolar do grupo dominante da parte social majoritária que ainda massifica, impondo seus modelos ainda vigentes de ensino/aprendizagem escolar. Mas que também abarca em seus manuais legais e teóricos as projeções libertadoras e libertárias entre outras perspectivas transformadoras que ocorrem pioneira e na prática nos dias atuais, e fazem parte de outra tendência educacional, estando no interior também do universo da parte social majoritária brasileira, por não poder em uma sociedade complexa ser monocultural o processo educacional e a transmissão dos saberes.

Ademais, é necessário o abandono de uma previsão negativa do desaparecimento físico dos indígenas. E, também negação da postura integracionista que buscava assimilar estes povos à comunidade nacional, negando o que tinham e têm de particular, porque eram vistos como categoria social e étnica transitória dada a extinção. A crescente mobilização social/indígena vêm conseguindo estabelecer uma nova forma de relacionamento, inclusive jurídico, entre as sociedades indígenas e 0 Estado brasileiro.

Neste ponto, referencia-se Canclini (2009) naquilo que se refere a temática da interculturalidade por considerar o conceito de cultura como hegemonizante, ou seja, este autor percebe que a "a diferença cultural é construída no próprio jogo do poder". E questiona: "sob que condições se administra as diferenças, as desigualdades e a inclusão/exclusão e os dispositivos de exploração em processos interculturais".

Se, portanto, o que pretende-se é uma educação em amplo sentido inclusiva, é mais que urgente que os planos se redefinam para uma educação voltada para uma 
profunda transformação na mentalidade de nossa espécie, construindo-se uma proposta educacional que ensine "a identidade terrenal", e remeta as nossas raízes no sentido da afirmação das diversidades identitárias que possam existir e resistir, estando em profundo acordo com "a consciência da identidade planetária".

A esperança que se tem é a luta dos povos por uma libertação das ideologias dominantes, e transformarem e construírem o novo. E, isso só se dá na práxis, unindo teoria e prática. De modo que se construam centros educacionais e/ou universidades que possam formar os agentes da transformação.

Por conseguinte, é preciso hoje se compreender os sete saberes postulados por Morin (2009), bastante cabíveis a proposta da construção dos novos rumos em geral para uma humanitária educação do futuro, sobretudo e necessariamente inclusiva, mas ampla no sentido de igualar educacionalmente a espécie humana mediante tantas diversidades e pior ainda tantos retrocessos e bloqueios cognitivos.

Segundo Morin (2000) a humanidade, em um primeiro lugar, precisa despertar para "uma educação que cure a cegueira do conhecimento". Isto é, uma educação que capacite 0 educando em geral a refletir sobre o próprio conhecimento no sentido de reconhecimento de erros e ilusões vinculados ao mesmo.

Numa nova educação, do futuro, como um segundo ponto da perspectiva do autor dar-se-ia a pertinência dos conteúdos. Esta nova forma de lidar com o conhecimento levaria a compreender problemas globais e fundamentais. Não existindo dicotomia entre o indivíduo e o bem comum ou "o conhecimento pertinente" que consegue ser simultaneamente geral e particular.

Já o terceiro item de sua proposta, sugere que a educação ensine a condição humana entendida como unidade complexa da natureza dos indivíduos. $E$, enfaticamente reconhecedora da diversidade cultural implícita em todos seres humanos.

O outro ponto abordado, o quarto saber, refere-se as relações humanas mediante uma perspectiva global. Construir um autêntico sentimento internacionalista de pertencer a terra. Uma educação que ensine a identidade terráquea, com uma profunda interculturalidade que volte a unir o disperso para uma consciência antropológica, ecológica, ética e espiritual.

Por exemplo, os Funió (povo indígena nordestino do interior de Pernambuco, com aproximadamente 2788 pessoas em 1989 e cerca de 4000 em 2014), e que contam inclusive com um dicionário bilíngue (Funió português e vice-versa) não tem acesso a cursos universitários como deveriam ter. Em um sentido geral, há, no Brasil, cerca de 305 etnias indígenas e ainda embrionárias universidades indígenas. Isto é um exemplo de violência simbólica. Daí que unir o disperso no Brasil seria a valorização destas populações das periferias. 
Outra situação dispersa indicativa desta necessidade de senso universalista, é a dos 43 estudantes mexicanos que foram torturados e/ou assassinados, e que segundo 0 relato de cerca de 20 sobreviventes, cinco foram encontrados mortos, eram normalistas indígenas, e foram capturados pelas polícias locais. Este acontecimento isolado faz parte de um genocídio maior que busca "vigiar e punir" aqueles que ousam resistir.

Tanto no México como no Brasil, as torturas e as mortes estão acontecendo em pleno sistema democrático, onde acontecem recentes eleições. A violência faz parte intrínseca do Estado que é o grande regulador sempre em favor das classes privilegiadas e dominantes. A educação seja no Brasil, seja no México ou qualquer de nossos países, estando sobre o controle do Estado ou aparelho similar estará controlado pelas elites dominantes.

No quinto saber exposto por Morin (2009), o mesmo reafirma que o que se precisa é de uma educação que ensine a enfrentar as incertezas. Ou seja, "Navegamos em um oceano de incertezas em alguns arquipélagos de certeza e não vice-versa", pois 0 futuro é imprevisível. E, não se pode ter a certeza dos positivistas do século XIX que acreditavam na evolução inexorável da sociedade com seu lema de ordem e progresso.

Além da necessidade de uma educação que incorpore o princípio de incerteza, é necessário também que se compreenda o conhecimento como relativo, contextualizado em seu tempo, portanto limitado. A isto, soma-se uma profunda humildade que todos os educadores devem ter em relação aos seus educandos, a capacidade de desenvolver um verdadeiro poder crítico para consolidar uma efetiva democracia.

A educação do futuro que necessita-se hoje retoma Sócrates "só sei que nada sei", ou seja, a compreensão que o conhecimento é limitado. E o espanto diante disto é necessário para todo educador que ouse resistir ao sistema que quer provar que 0 agora é o fim da história. $E$, que há uma única alternativa de vida possível para os povos, e que não há futuro. Ao contrário. Acredita-se: "que o outro mundo é possível", que "carregamos um mundo novo em nossos corações".

Ademais é preciso se dizer que as novas descobertas científicas muitas vezes destroem antigas capacidades; e novos paradigmas são construídos em cima de destroços de paradigmas anteriores. Ou seja, categorias inteiras de trabalhadores especializados tornam-se obsoletos da noite para o dia. Qual é o papel da educação com tantas incertezas. Se deve construir uma pedagogia libertadora dos oprimidos: pensar, criticar, repensar e transformar a realidade. E, neste sentido, é fundamental ter em mente que esta educação têm a capacidade de formar pessoas que possam enfrentar as incertezas.

O sexto item levantado por Morin (2000) requer uma reforma de mentalidades para superar os males sociais como o racismo, a xenofobia, o machismo, a homofobia e outras opressões. Trata-se de uma educação que ensine 0 aprendizado da 
compreensão, porque a educação do futuro deverá assumir os compromissos com as democracias. Somente as democracias diretas, onde se tenham construído poderes realmente populares, realizam a compreensão em escala planetária. Segundo o autor: "ensinar a compreensão significa ensinar a não reduzir 0 ser humano a uma ou várias de suas qualidades que são múltiplas e complexas", e, portanto não rotular ou "etiquetar" as pessoas.

O ser humano é muito mais do que um simples dado aparente. Daí ensinar a simpatia com os humanos do nosso planeta, e uma tolerância que esteja de acordo com a dignidade humana, valorizando a diversidade étnica e cultural do nosso continente. 0 egoísmo, o etnocentrismo, etc, o capitalismo de uma forma geral, gera relações desarmônicas. Inclusive no que se refere à educação, este tipo de relacionamento, é destrutivo.

Pode-se superar, e não viver hoje em um mundo onde a espécie humana coloca em risco de extinção não somente toda humanidade, mas também a todas as criaturas vivas. A intervenção desordenada no meio ambiente atinge níveis críticos e todos os seres vivos estão ameaçados de extinção.

Os educadores mais conscientes precisam trabalhar para a constituição de uma tendência mais libertadora e libertária da educação. Este ensino da compreensão a nível planetário é importantíssimo para a construção de um futuro, pois a realidade não se resolve em um esquema dialético de tese, antítese e síntese. Há infinitas variantes complementares e antagônicas entre si, não é uma simples síntese, é algo mais complexo. Vive-se na sociedade da comunicação. Mas comunicação não implica somente em compreensão, este conceito deve ser pensado sob uma escala planetária, num sentido de fortalecimento de sociedades verdadeiramente democráticas, pois fora da construção do emponderamento de povos excluídos não existe tolerância ou liberdade.

O sétimo ponto discutido por Morin (2009) propõe uma ética global, baseada na consciência do ser humano como indivíduo e parte da sociedade e da espécie. Democracia não se identifica com ditadura das maiorias, trata-se de um respeito as diversidades em todos os níveis. A humanidade não é mais um conceito abstrato e distante. Tornou-se uma obrigação planetária ensinar a compreensão de que somos cidadãos terrestres. Isso não só garante as especificidades dos diversos povos, como estabelece uma ética do futuro que tanto se necessita hoje.

Esta ética do gênero humano é uma conquista. É uma exigência do nosso tempo, não cabe mais etnocentrismos ou propostas iluministas a partir de um centrocolonizador, os tempos das colônias e das metrópoles definitivamente acabaram. Deve-se construir um mundo livre, que respeite as diversidades e os antagonismos sem massacres e genocídios, o que se precisa é olhar por outro ângulo ou como disse Albert Einsten: "Tolice é fazer as coisas do mesmo jeito e aguardar resultados diferentes.". 
É preciso hoje se construir a educação do futuro no bairro, nas aldeias, na América Latina e no mundo. É preciso que o sistema educacional não seja meramente reprodutivista, Mas que prepare a humanidade para novos passos, donde 0 conhecimento multidimensional e interativo sempre seja geral e específico, e que desenvolva esta consciência antropológica, ecológica e ética. Esta tarefa de contribuir para o sistema educacional do futuro parte de uma urgência imediata de se trabalhar imediatamente, tendo em vista as valiosas contribuições do citado pensador Morin.

Outro ponto a se abordar em definitivo é o entendimento de que tradicional é completamente diferente de arcaico, obsoleto. O futuro tem história fincada em raízes profundas construídas no passado, o lema: "liberdade ou morte" dos 33 orientais é uma dessas raízes que foram retomadas na construção de um sistema de ensino público de qualidade, obrigatório e laico, que buscava reformar e formar cidadãos. Este sistema educativo que Pedro Varela, ministro e reformador da educação no Uruguai buscou implementar em seu país mediante a construção da identidade e da soberania nacional serve perfeitamente para se pensar num ensino internacionalizado a nível de ensino superior com uma tendência que vive-se hoje, buscando não mais a soberania nacional no Uruguai por exemplo ou em qualquer outro país ou contexto local mundial. E, sim a construção da consciência planetária proposta por Edgar Morin.

Como um pássaro que empurra o chão para conseguir voar. Devem-se buscar as tradições no sentido de se construir um mundo melhor com base firme em um passado, e a partir do bem enraizado realizar-se um futuro mais pleno.

\section{5.-Conclusão.}

Por tanto, finaliza-se citando Freire (1987) uma vez que sua teoria sempre procurou construtivamente incluir, e dando uma valiosa pista aos educadores e a fim de como proceder, isto é, para ele "A palavra é a chave de libertação do oprimido". E, também as pontes dialógicas da travessia para um mundo mais pleno. Nas próprias palavras do autor:

Esta é outra dimensão fundamental da teoria da ação opressora, tão velha quanto a opressão mesma. Na medida em que as minorias submetendo-se as maiorias a seu domínio, as oprimem, dividi-las e mantê-las divididas são a condição indispensável à continuidade de seu poder. (Freire, 1987; p.79)

A teoria da ação antidialógica ainda impera em grande parte das relações humanas e sociais. A invasão cultural continua se servindo de expansão de domínios e conquistas, desrespeitando potencialidades do ser que, em muitas das vezes, condiciona este processo de mudanças.

"Esta "invasão cultural" é a penetração que fazem os invasores no contexto cultural dos invadidos, impondo a estes sua visão de mundo, enquanto lhe freia a criatividade ao inibirem sua expansão." (Freire, 1987; p.86). Daí a importância de se procurar 
fazer como o pensador-educador, colocar sempre em prática a ação dialógica, levando em consideração seus elementos, expostos pelo autor aqui referenciado: "colaboração, respeito a expressão do outro, união e síntese cultural." É esta uma boa receita para realizar-se a necessária travessia educacional, inovadora e de fato inclusiva rumo ao mundo diverso e pleno que se espera surgir.

\section{6.-Referências Bibliográficas.}

Bardin, L. (2005). Análise de conteúdo. Trad. Reto, L.A., Pinheiro, A. Lisboa: Ed. 70, 2004. Becker, J.S., Marcel, G. A intersubjetividade participativa na relação Eu Tu. In: Maas, A. Linguagem, Escrita e Mundo. ljuí: Universidade Estadual de ljui.

Canclini, N.G. (2009). Diferentes, Desiguales y Desconectados. Mapas de La Interculturalidad. Costa Rica: Universidad de la Costa Rica.

Freire, P. (1987). Pedagogia do Oprimido. Rio de Janeiro: Paz e Terra.

Kuhn, T. (1998). A estrutura das revoluções científicas. São Paulo: Perspectivas.

Marconi, M. A., Lakatos, E. M. (2009). Fundamentos em metodologia científica. 6.ed. São Paulo: Atlas.

Morin, E. (2009). Os Sete Saberes Necessários para a Educação do Futuro. São Paulo: Cortez.

Morin, E., Cunha, C. (2000). Uma educação adaptada à sociedade globalizada. São Paulo: Edix Edições.

Morin, E. (coord.). (2000). Religando os saberes. Rio de Janeiro: Bertrand. 